\title{
AUTOMATED SYSTEM FOR TARGETED SPRAYING IN ORCHARDS BY USING RGB IMAGING
}

\author{
StAJNKO, D.; Vindis, P. \& MURSEC, B.
}

Abstract: At present fruit orchards are sprayed mainly with axial fan 'mistblower' orchard sprayers, which are known on huge spray drift, which leads to large losses of pesticides. A newel automated orchard sprayer is represented, which can deliver pesticide spray selectively with respect to the characteristics of the targets. The shape of the apple tree canopy was detected by a machine vision system using an RGB camera and appropriate image analysis. Information captured by RGB camera and processed by specific software was fed in real-time to a spraying arm, with three individually controlled sections, which adapt the pesticide spray flow to the canopy shape. The system allows variation in the liquid flow rate and volume of chemicals by means of controlled electric valves, whereby the amount of spray depends on the shape of the tree crowns.

Key words: air-assisted sprayer, algorithm, automated arm, image analysis, spray distribution
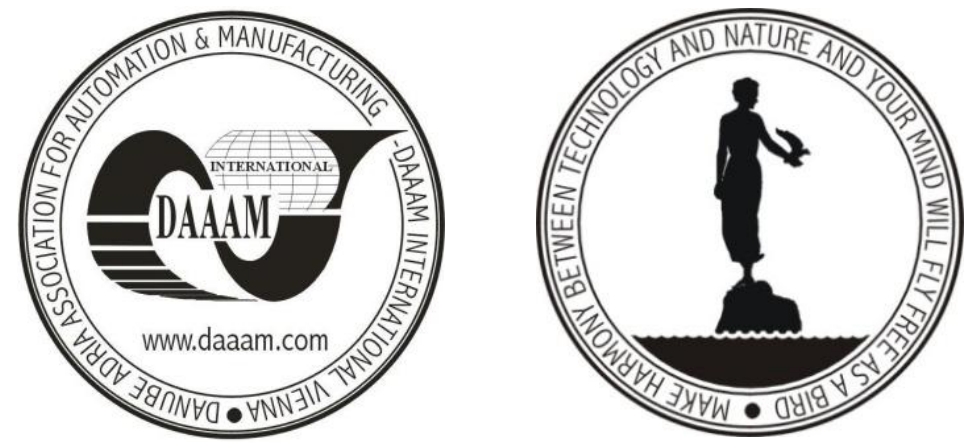

Authors' data: Assoc. Prof. Stajnko, D[enis]; Bs. Agric. Eng. Vindis, P[eter]; Ph. Agric. Eng., Assoc. Prof. Mursec, B[ogomir], University of Maribor, Faculty of Agriculture and Life Sciences, Pivola 10, SI-2311, Hoče (Maribor), Slovenia, denis.stajnko@uni-mb.si, peter.vindis@uni-mb.si,peter.berk@uni-mb.si

This Publication has to be referred as: Stajnko, D[enis]; Vindis, P[eter] \& Mursec, B [ogomir] (2011). Estimation of Bull Live Weight Using Thermal Imaging, Chapter 23 in DAAAM International Scientific Book 2011, pp. 283-300, B. Katalinic (Ed.), Published by DAAAM International, ISBN 978-3-901509-84-1, ISSN 1726-9687, Vienna, Austria

DOI: 11.2507/daaam.scibook.2011.23 


\section{Introduction}

Nowadays fruit orchards are sprayed mainly with axial fan 'mistblower' orchard sprayers. The axial fan design is favoured because it is effective in a wide range of types of orchard and under a wide range of conditions. These sprayers are simple, robust, reliable and of comparatively low cost in terms of purchase and operation. Unfortunately, the large radial spray plume generated by axial fan orchard sprayers - often over $5 \mathrm{~m}$ in radius - is prone to spray drift, and large losses to the ground occur (Cross et al. 2001). Possibilities for adapting the characteristics of sprayer air flow to different tree canopies are quite limited.

A number of systems for adjusting the applied dose of plant protection products according to orchard structure have been developed in the past decades. One of wide accepted is the Tree Row Volume (TRV) system initiated by Byers et al. (1971). In this system, the dose applied to an orchard is varied by varying the spray volume at constant pesticide concentration in proportion to the TRV. The TRV $\left(\mathrm{m}^{3}\right.$ $\left.\mathrm{ha}^{-1}\right)$ is the volume of the tree canopy per unit of ground area $(=10000 \mathrm{x}$ crown height $\mathrm{x}$ limb spread / row spacing). The TRV spray volume adjustment system has been adapted and tested for low volume spraying in several European countries (Sutton \& Unrath 1984, 1988; Heijne et al. 1997). In contrast to TRV model, Pergher et al. (1997) and Pergher \& Petris (2008) proposed the use of leaf area measurements to improve the correlation between deposits given by different types of spraying equipment and types of hedgerow vineyards. However, the different shapes and sizes of tree canopies, even among the same variety in the orchard, require continual calculation of TRV and adjustment of the applied dose of pesticide to optimise the spray application efficiency (Solanelles et al. 2006).

There is also a simplified concept presented by Weisser \& Koch (2002) who propose to calculate the dose of pesticide according to the tree canopy green wall area. Koch et al. (1998) and Koch \& Weisser (2000) demonstrated that principle of dosing according to green wall area is applicable. It shows how overlapping of single nozzle fans create the total distribution pattern of sprayer. For the moment the dosing system for orchards are still under development and evaluation.

For those reasons, in the last 10 years measurement of crop structure has been simplified by the development of a range of non-invasive optical and ultrasonic sampling techniques. In particular, the development of a compact, tractor-mounted light detection and range (LIDAR) system has made it possible to take quick and detailed readings of crop structure (Wangler et al. 1993). These are suitable for computational processing to calculate a wide range of summary parameters based on a probabilist interpretation of light transmission and crop interception characteristics (Walklate et al. 2002). Such a system employs a pulse time-of-flight ranging method, with separate apertures (side-by-side) for an infrared laser diode transmitter and a matched diode light receiver.

Contrary to the expensive radar system, Gil et al. (2007) suggested the use of ultrasonic sensors and proportional electro-valves with the corresponding software and automation, which allowed real time modification of the sprayed flow rate 
adapted to the crop structure of the vineyard. In response to changes in the shape and size of the vines during the growing season, this system reduced the spray volume and the use of pesticides by up to $57 \%$, while maintaining coverage and penetration rates similar to those from conventional spraying methods.

Considering that ultrasonic sensors were originally designed to measure distances in industrial environments, where objects are rigid, and the surface of rebound is perpendicular to the direction of the ultrasonic wave, their utility in orchard measuring might be negligible. Moltó et al. (2000) showed that ultrasound sensors measured the distance of the tree canopy with an expected error of $11.40 \mathrm{~cm}$, which could prevent the control system from accurately differentiating the hollows in the foliage from the space between two consecutive trees. Moreover, Schumann \& Zaman (2005) showed, that the accuracy and repeatability of ultrasonic measurement was lower than manual measurement at a driven speed of $1.0-1.5 \mathrm{~ms}^{-1}$, for both height and volume measurements was best with smaller citrus trees $\left(3.14 \mathrm{~m}^{3} \operatorname{tree}^{-1}\right)$.

Recently, a review of methods for targeted crop protection systems in agriculture was given by Van de Zande et al. (2008). It was shown that solutions for targeted spraying of pesticides in orchards are still in prototype phase, however, there are already commercially available sprayers for weed control and plant fertilizing in the arable land.

Potential enhancement of the ultrasonic and radar approach can be achieved with the aid of RGB image acquisition and analysis. Recently, the Hough-transformbased vision algorithm for crop row detection of an automated agricultural vehicle was reported to be the most promising method in orchard management (Kise et al. 2005; Rovira-Más et al. 2005).

The purpose of our research was to develop an automated orchard sprayer consisting of a radial fan and hydraulically driven spraying arms with nozzles controlled by an RGB image processing system. Results on comparisons of spray coverage characteristics as well as the savings of pesticides between two working modes (with and without automated guidance) and two air outlet configurations (straight vertical and angled) are presented.

\section{Technical characteristics of the RGB supported sprayer}

\subsection{Testing design}

The spray distribution and coverage measurements presented are the outcome of experiments carried out in the research orchard of Brdo pri Lukovici $\left(46^{\circ} 10^{\prime} \mathrm{N}\right.$, $14^{\circ} 40^{\prime} \mathrm{E}$ ), owned by the Agricultural Institute of Slovenia. Spraying without using automated guidance (control spraying mode) was compared with novel spraying method using prototype automated sprayer guidance (automated spraying mode). The configuration of the sprayer is in full details explained in section 2.2.

The experiments were performed on spindle trained apple trees, shown in Figure 3 (left), which were a 12-year old 'Jonagold' variety grafted onto M9 rootstock at $1.5 \mathrm{~m}$ spacing and a row spacing of $3.5 \mathrm{~m}$. The average height of the trees was $3 \mathrm{~m}$. Continuous one side spraying of trees along the tree row was 
Stajnko, D.; Vindis, P. \& Mursec, B.: Automated System for Targeted Spraying in ...

performed. Within trees in the sprayed row, five groups consisting of three trees were selected for analysis of spray coverage. Each group of trees together with $20 \mathrm{~m}$ long track between two groups represented one statistical repetition of experimental measurements. The experiment was arranged with repetitions in a single row to ensure constant guiding and meteorological conditions. Any passing to other tree rows would immediately cause additional variability. During the tests the following mean values for the meteorological conditions were recorded: temperature 19.9$24.2^{\circ} \mathrm{C}$, relative humidity $60.8-75.8 \%$, wind speed $1.1-1.7 \mathrm{~ms}^{-1}$ and wind direction 16$41 \mathrm{deg}$ deviation from perpendicular direction of the sprayer track.

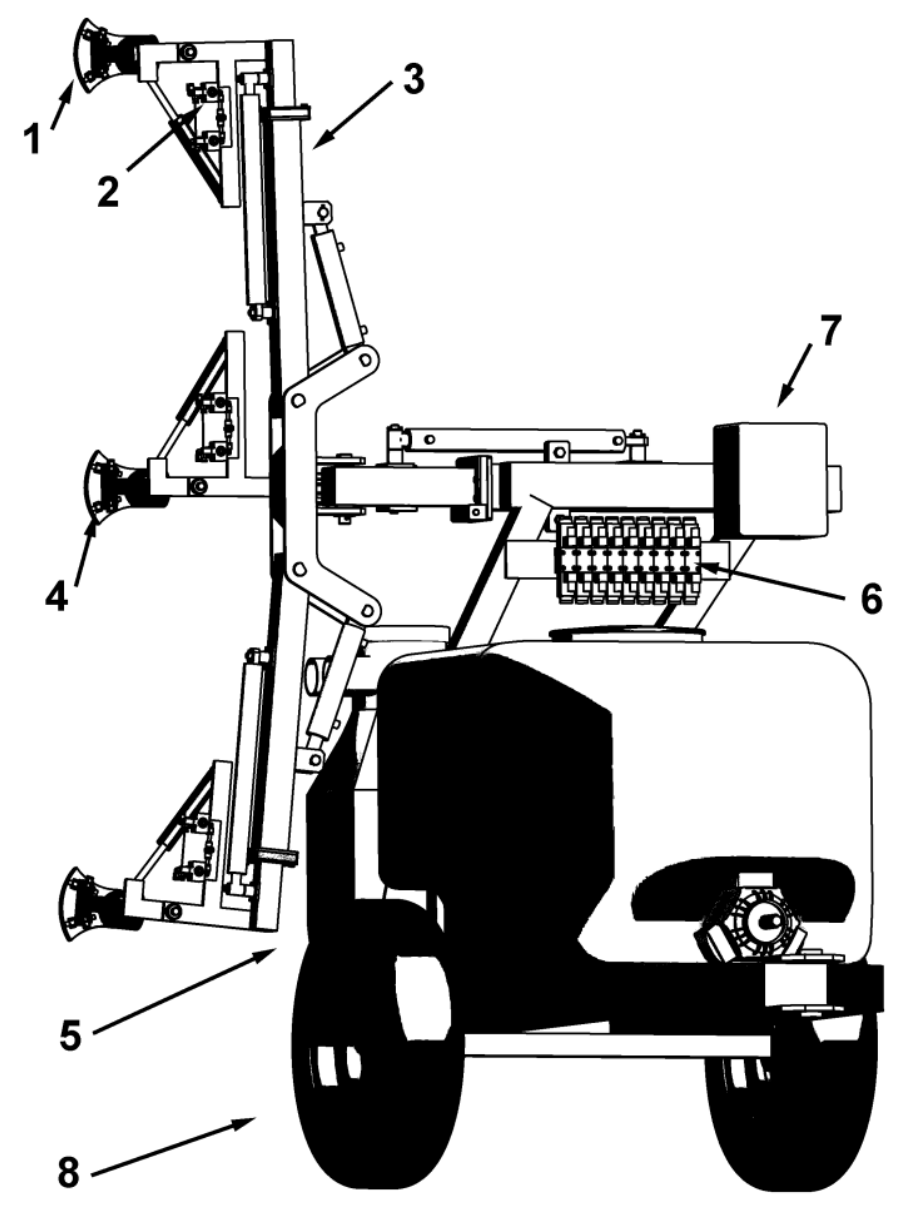

Fig. 1. An automatic sprayer with assembled parts: 1) deflector, 2) electro-valve for opening/closing of nozzle, 3) robot arm, 4) nozzle, 5) radial fan, 6) electro-hydraulic valves for robot arm adjustment, 7) electro distribution station, 8) trailed air-assisted sprayer

\subsection{Layout of the sprayer}

The prototype sprayer was developed by modification-upgrading of a trailed air-assisted sprayer (Agromehanika Kranj, Kranj, Slovenia), equipped with a piston pump and a 10001 tank. The blower unit and a special spraying arm were mounted on the trailed sprayer. The blower unit was a radial fan with a spiral casing and three airflow pipes leading from the spiral casing to each section (air outlet - spout) of the spraying arm. The spraying arm consisted of three individual sections: above, middle 
and below section, a division which enables distance, height and tilt adjustment (see Figs. 1 and 5). All adjustments of spraying arm were set from the tractor cabin. For this purpose, an electric installation connected to the hydraulic solenoid valves KVM P4/3-6-G1-12V/DC-3/8 (Kladivar, Ziri, Slovenia) was used. Each section comprises of a 2-nozzle boom with one electro-valve mounted on each nozzle. The sprayer was fully operative on one side. To avoid spraying at too low a pressure, an anti-drip device was mounted on each nozzle with an internal spring set to open at $1.5 \mathrm{bar}$.

\subsubsection{Sprayer operating in the control spraying mode}

The same sprayer was operated in different spraying modes. A bypass valve in the sprayer manifold allowed the prototype to work as a standard sprayer with three spouts having two nozzles per spout positioned straight vertical on top of each or with modified angled position of lower and upper spout. The position of the spraying arms at both control modes is presented in Fig. 2. Spraying with straight vertical position of all three spouts is denoted as "vertical control spraying mode" (VCM, see Tab. 5 left) and spraying with angled position of lower and upper spout is denoted as "modified control spraying mode" (MCM, see Tab. 5 right).

At VCM mode nozzles were set vertical on top of each other at $0.85 \mathrm{~m}$ from the tree crown edge. During the MCM the height of nozzles and the distance of nozzles from the edge of the tree canopy were adjusted to the structure of the tree crowns and set manually by the operator prior spraying. The spraying arms were not positioned vertically with spouts on top of each, but spouts were angled upward or downward (see Fig. 2 - right side). The top spout (nozzle body) was positioned on the distance $0.53 \mathrm{~m}$ and at the bottom spout (nozzle body) on $0.6 \mathrm{~m}$ distance from the tree crown edge. All six nozzles of the sprayer were opened in the control spraying mode all the time. During the control spraying mode, none of the three sprayer sections were controlled by guidance system, as it is the case with standard radial sprayers already in use.
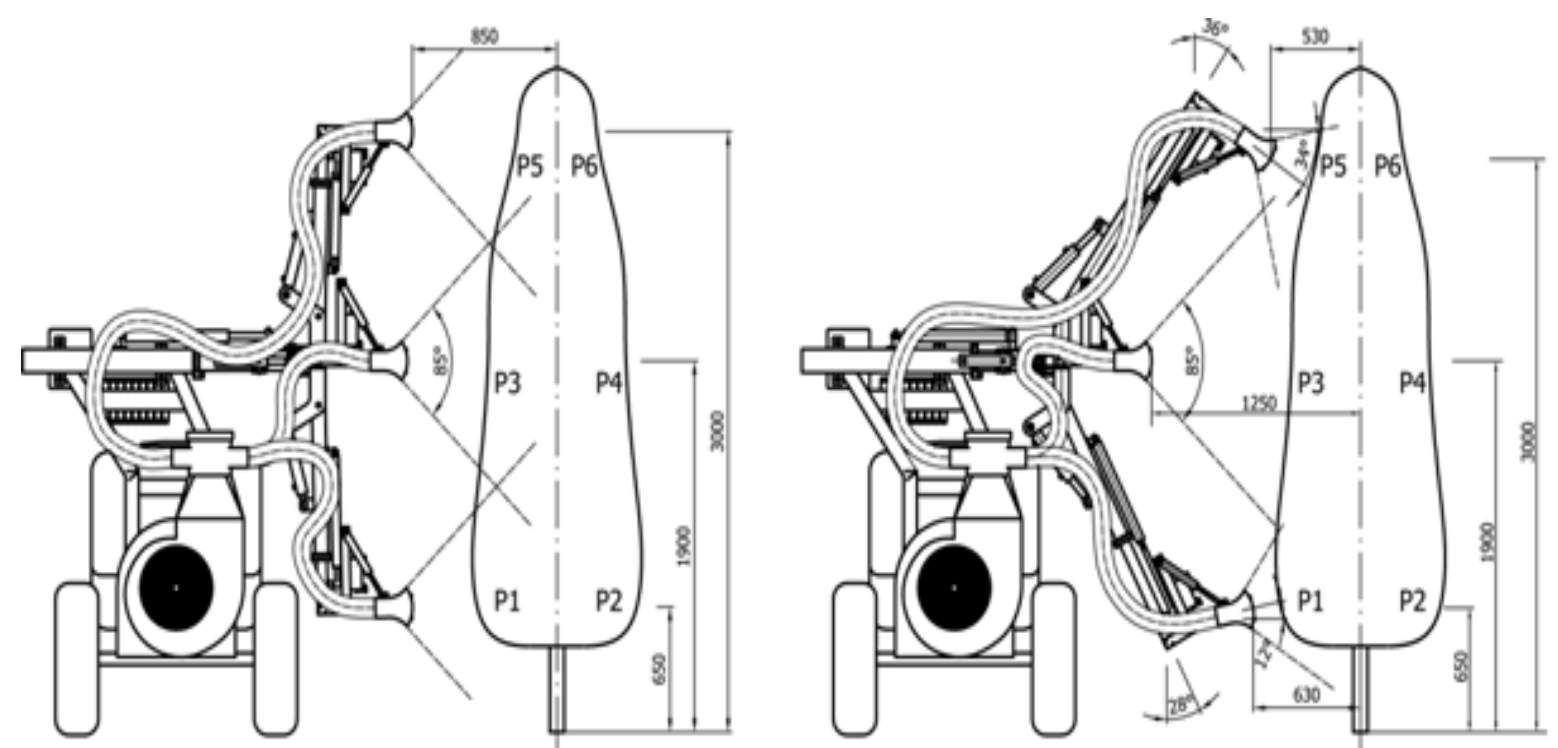

Fig. 2. Scheme of WSP positioning on the tree during conventional (left) and automated spraying (right) 
Stajnko, D.; Vindis, P. \& Mursec, B.: Automated System for Targeted Spraying in ...

\subsubsection{Sprayer operating in the automated spraying mode}

During the automated spraying mode (AM) nozzles were not open constantly, but opening or closing of nozzles was controlled online by the image acquisition and analysis system. For the AM we present just the data on operating with angled spouts, because there were no differences in acquisition of canopy structure pictures between vertical and angled spout configuration. The camera is mounted in front of tractor (Fig. 3 left).

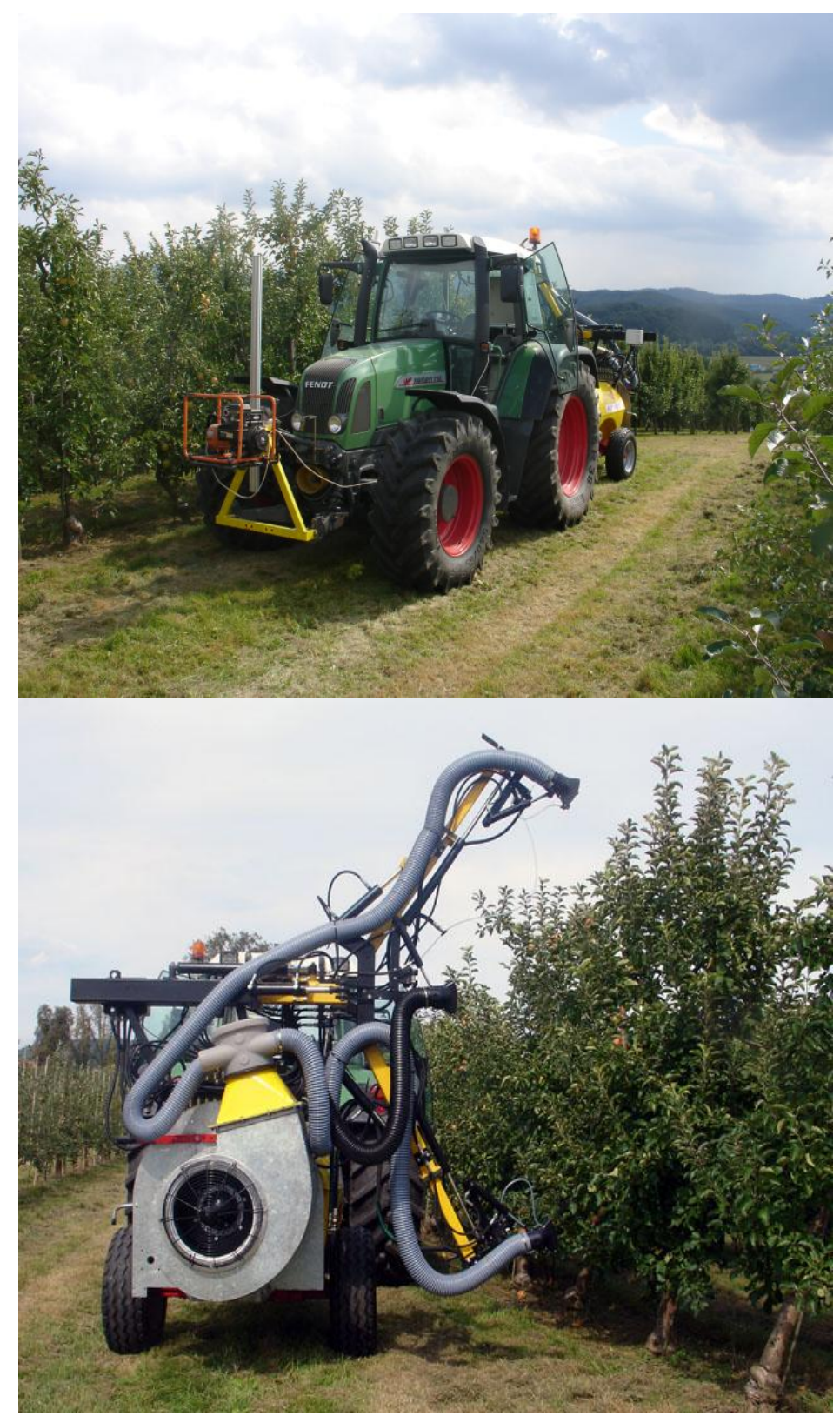

Fig. 3. A prototype automated sprayer mounted on the tractor

\subsection{Operational conditions of the orchard sprayer}

The spraying was performed at forward speed of $1.47 \mathrm{~ms}^{-1}\left(5.30 \mathrm{kmh}^{-1}\right)$ for both spraying modes. Characterization of the air stream was obtained with a 3D ultrasonic anemometer (Young 81000, R.M. Young Co., Traverse City, MI, USA). To ensure proper sampling, air velocities were measured for each of three spouts separately in an axial horizontal direction, $500 \mathrm{~mm}$ apart from the spouts and the 
nozzles where the air jet was wider than the diameter of the anemometer sample volume $(100 \mathrm{~mm})$. For all tests, the PTO rotational speed was $540 \mathrm{~min}^{-1}$. This gave a mean air volumetric flow rate of $4.13 \mathrm{~m}^{3} \mathrm{~s}^{-1}$ and a mean air velocity of $15.8 \mathrm{~ms}^{-1}$.

The sprayer was equipped with six hollow cone nozzles (TeeJet TXA8001VK orange) operating with a pressure drop of 8.0 bar, to give total spray flow rates of 4.2 $1 \mathrm{~min}^{-1}$. Thus, the maximum range of values for the applied spray volume per unit of ground area was $2721 \mathrm{ha}^{-1}$, when all the nozzles were opened. The sprayer settings (Tab. 1) were the same for both treatments.

The pump used was a four piston semi-hydraulic diaphragm pump model (PA 154, Idromeccanica Bertolini, Reggio Emilia, Italy) with volume flow $142 \mathrm{lmin}^{-1}$ at a selected rotational speed $540 \mathrm{~min}^{-1}$. The volume flow of the pump was over 200 times the flow through the individual nozzle, thus we assumed that opening/closing of one or several nozzles did not change the pressure and mean droplet size of other nozzles. The rotational speed of the pump was electronically controlled by the tractor during both experiments.

\begin{tabular}{ll}
\hline & Operational parameters \\
\hline Nozzle serial number & 8001 \\
Colour & Orange \\
No. of active nozzles per side & 6 \\
Pressure (bar) & $8 \mathrm{bar}$ \\
Spray flow rate per nozzle $\left(\mathrm{min}^{-1}\right)$ & $0-0.7$ \\
Spray flow rate all nozzles $\left(1 \mathrm{~min}^{-1}\right)$ & $0-4.2$ \\
Forward speed $\left(\mathrm{km} \mathrm{h}^{-1}\right)$ & 5.3 \\
Working width $(\mathrm{m})$ & 1.75 \\
Reference application rate $\left(1 \mathrm{ha}^{-1}\right)$ & 262 \\
PTO speed $(\mathrm{rev}$ min & -1 \\
Volumetric air flow rate $\left(\mathrm{m}^{3} \mathrm{~s}^{-1}\right)$ & 540 \\
\hline
\end{tabular}

Tab. 1. Operational parameters during treatments

\subsection{Imaging and control system}

The imaging system of the prototype automated sprayer consisted of a FireWire RGB camera Flea 2 from Pointgrey Research with Sony ICX204 1/3" and an image-processing computer. The camera was set to a resolution of $1024 \times 768$ pixels with $2 \times 2$ binning. The $6.3 \mathrm{~mm} \mathrm{~F} / 1.9 \mu$-video lens with C-mount adapter was used. The camera was located $50 \mathrm{~cm}$ in front of the tractor and $100 \mathrm{~cm}$ above the ground, so the final position was $700 \mathrm{~cm}$ in front of the spraying arm (Fig. 3).

To capture the whole tree surface vertically, the camera was rotated $90^{\circ}$ around its axis so the image was $768 \times 1024$ pixels (Fig. 4). The camera was also pointed upwards at the angle of $30^{\circ}$ in order to capture the entire crown. This also enabled the separation of leaves from the background sky with HSL extraction as described later. 
Stajnko, D.; Vindis, P. \& Mursec, B.: Automated System for Targeted Spraying in ...

All camera settings were set before the experiment, so the camera was not moving or rotating during operation.
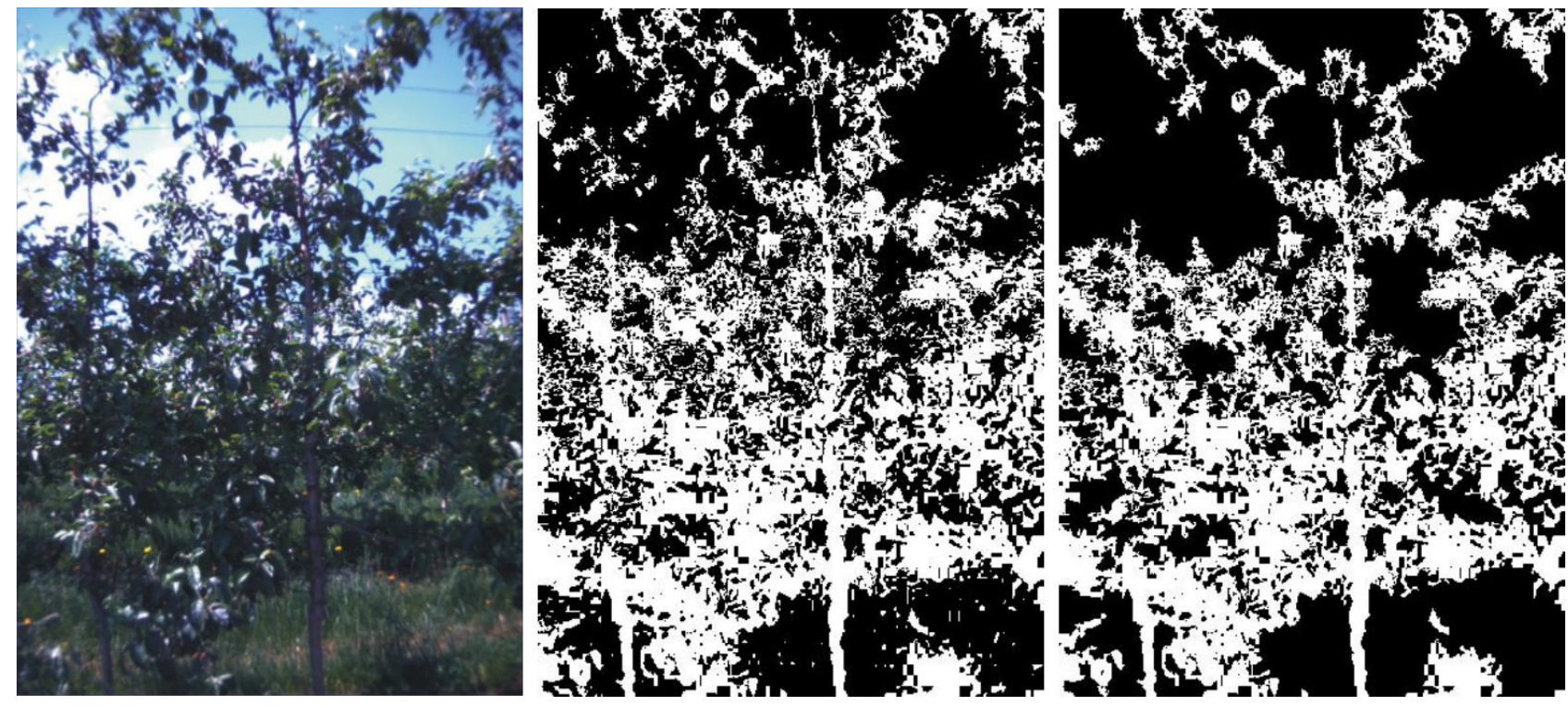

Fig. 4. Sample image, acquired image (left), image after HSL extraction (middle) and image after erosion (right)

Images were acquired at a frequency of $3.75 \mathrm{~Hz}$, which produced at a driving speed of $1.5 \mathrm{~m} \mathrm{~s}^{-1}$ one picture every $0.40 \mathrm{~m}$ and ensured approximately 70 percent overlapping of images. The exposure time was set manually to $1 / 1000 \mathrm{~s}$. We used camera's automated feature for gain, brightness, gamma, hue, pan and saturation.

The image analysis algorithm consisted of hue/saturation/luminance (HSL) extraction and erosion. HSL extraction was used to extract green and reject other colour components. The lower and upper limits for hue were $110^{\circ}$ and $160^{\circ}$. The lower and upper limits for saturation were 30 and 200, while limits for luminance were 0 and 100 for $0-255$ interval. Settings were set before the start of experiments and were selected according to the illumination conditions. After green was extracted, the erosion algorithm was used to retain particles resistant to three consecutive erosions with a square $3 \times 3$ structuring element. The particles retained were exactly the same size and shape as those found in the original image after HSL extraction. A sample acquired image, an image after HSL extraction and an image after erosion are shown in Fig. 4.

The resulting image was cut into three sections: above, middle and below, corresponding to each arm section location (Fig. 5).

In each section, the number of pixels remaining after analysis was counted in sliding windows $50 \times 170$ pixels in size. Thus, we generated a profile of light intensity of leaves in each image. These profiles of intensity were averaged, owing to the overlap occurring during image acquisition, and then filtered by a low pass Butterworth filter of the second order with cut-off frequency $50 \mathrm{~Hz}$. Since the arm was mounted $7 \mathrm{~m}$ behind the camera, the intensity profiles were kept in memory for a time corresponding to the time delay of the arm action. Profiles of the intensity at the location of the spraying arm were used to control the openings of the nozzles. If the 
intensity at the location of the arm was higher than a set threshold, the spraying nozzle valves were opened; otherwise the spraying nozzles valves remained closed. The thresholds were set before each set of spraying.

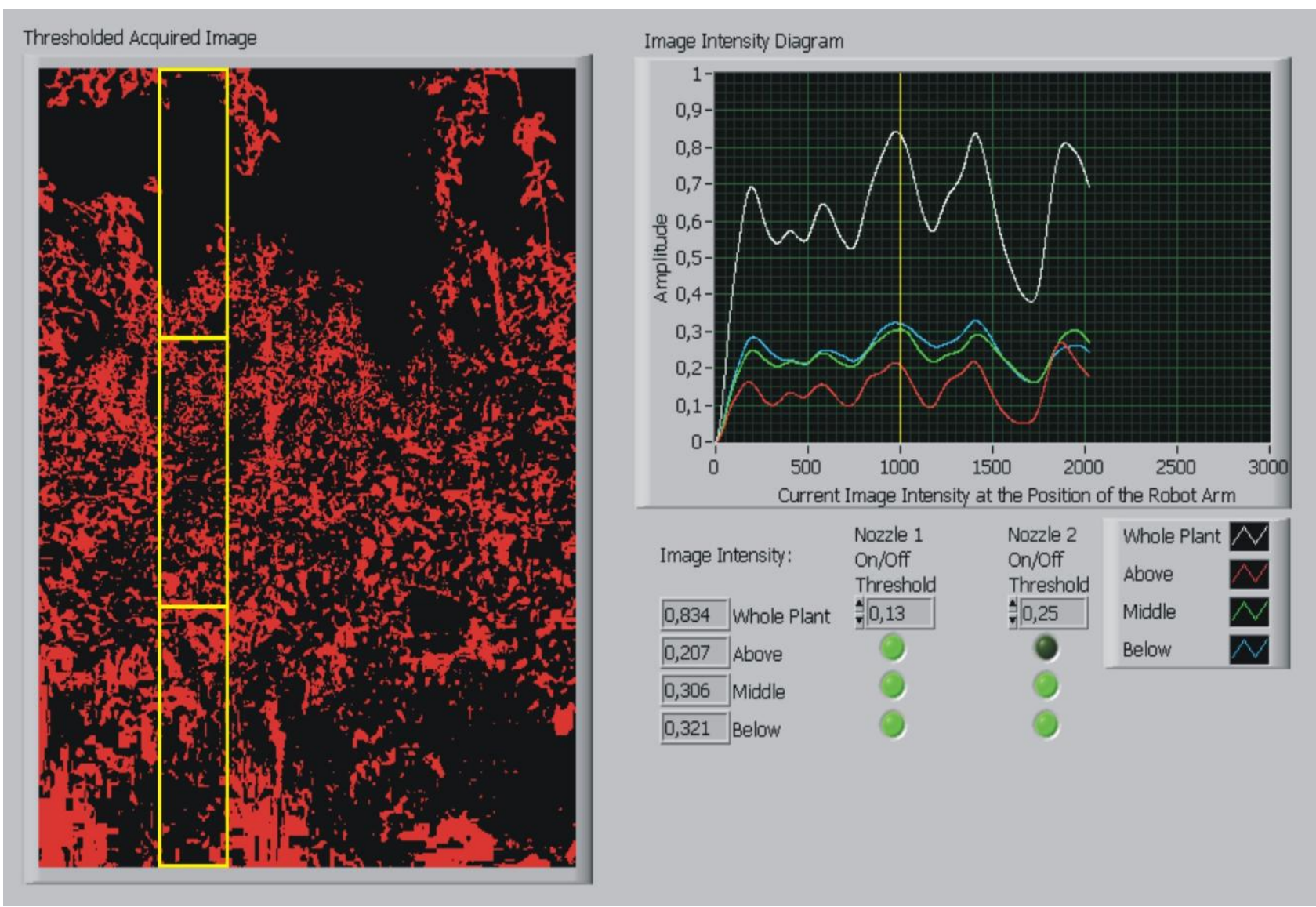

Fig. 5. Front panel showing the intensity profiles of three sections (left), average profile (diagram right and above) and the status of nozzles (right and below, round indicators)

The threshold was two-fold: the threshold for the first nozzle of each pair was set at 0.13, while the threshold for the second nozzle of each pair was 0.25 . A threshold value 1 corresponded with pixels representing $100 \%$ leaf coverage, while a value 0 corresponded with $0 \%$ leaf coverage. Therefore the first nozzle opens at $>13 \%$ coverage and the second nozzle opens at $>25 \%$ coverage.

Different selection of HSL extraction algorithm settings would require different settings of threshold values. The same thresholds were used for all three arm sections. Since both nozzles in each nozzle pair were located only $110 \mathrm{~mm}$ apart, their sequence of operation was unimportant.

We used software based on the National Instruments Labview and National Instruments Vision package. For image acquisition and processing, the embedded fanless computer IEI ECK - $3692 \mathrm{G}$ with Intel Core 2 Duo $1.66 \mathrm{GHz}$ processor was used.

The nozzles were opened using a data acquisition board from National Instruments 6008, with static digital output of the TTL type. For activating/deactivating the pesticide flow through the nozzles, direct-acting solenoid 
Stajnko, D.; Vindis, P. \& Mursec, B.: Automated System for Targeted Spraying in ... valves D220 12V/DC (Jaksa, Ljubljana, Slovenia), connected through Weidmüller RS30 relays were used.

\subsection{Spray flow rate calculation}

The different components and the control system were tested and fine-tuned in the laboratory and on artificial trees; later, when the sprayer prototype was fully assembled, it was tested in the orchard. This process resulted in a real-time system for the continuous opening and closing of all six nozzles according to the tree canopy structure. The real-time flow rate of each electro-valve controlled nozzle of the sprayer prototype was computed as follows:

$$
q=p \cdot\left(\frac{a \cdot v \cdot V_{r}}{600 \cdot N}\right)
$$

where: $a$ is a half working width of 6 nozzles; $v$ is the speed in $\mathrm{km} \mathrm{h}^{-1} ; V_{\mathrm{r}}$ is the volume application rate for the orchard in $1 \mathrm{ha}^{-1} ; \mathrm{N}$ is the number of nozzles; and $p$ is the reduction coefficient of the maximum flow rate given by the formula:

$$
p=\frac{\sum t_{i}}{\sum t}
$$

where: $\sum t_{i}$ is the sum of actual opening time for each nozzle, $\sum \mathrm{t}$ is the sum of maximum possible opening time for all nozzles.

\subsection{Analysis of spray coverage}

In order to quantify the spray coverage and to study the penetration efficiency of the drops resulting from different spray modes, Water Sensitive Papers (75 x 26 $\mathrm{mm}$, WSP, Novartis, Basle, Switzerland) were placed every time on the same places in the each of five groups of trees immediately before each spraying as proposed by Cross et al. (2001). The WSP were collected approximately 10 min after they had completely dried.

Each selected tree was divided into six zones. In each zone, one facing upward and one downward, WSP paper was used as shown in Figure 5, according to the following parameters:

a) depth: external (with WSP placed at an approximate distance of $10 \mathrm{~cm}$ from the exterior, in front of the centre of the tree trunk - P1, P3, P5) and internal (at an approximate distance of $50 \mathrm{~cm}$ from the imaginary axis that passes through the centre of the trunk, behind the tree trunk- P2, P4, P6);

b) position on the tree: two papers (bottom and leaf side) were clipped by horizontal plastic clips to small branches at $1 / 3$ of the tree height $(650 \mathrm{~mm})-\mathrm{P} 1, \mathrm{P} 2$, in the centre of the tree $(1900 \mathrm{~mm})-\mathrm{P} 3, \mathrm{P} 4$, and at $2 / 3$ of the tree height $(3000 \mathrm{~mm})$ P5, P6. 
Data presented are average values of measurements from upper and lower side of WSP at each specific position. Images of each WSP were digitized using the Optomax Image Analysis system (Optomax, Hollis, City, NH, USA), consisting of a CCD camera with a zoom lens, a monitor to control the picture being analyzed, and a PC with a Frame Grabber card. The area resolution of the system was 1/417600 per field of view $(720 \times 580$ pixels), so the smallest spot size detected by 1 pixel was 8 $\mu \mathrm{m}$ and image depth was 256 grey levels (Holownicki et al. 2002b). By using this system, coverage (with stains covered area - \% coverage) the number of impacts and the number of impacts per area were all analyzed.

All data were transferred from Optomax to formatted computer spread-sheets (Microsoft Excel) before statistical analysis of variance (2 treatments x 5 repetitions $\mathrm{x}$ 6 locations) using the SPSS 16.0 Package Program.

\section{Results and discussion}

\subsection{Spray distribution and coverage}

The quality of spray distribution determined by analysis of WSP samples was expressed as the number of impacts per $\mathrm{cm}^{-2}$ and the percentage of coverage. Tab. 2 shows the results on comparison of VCM and MCM spraying modes.

\begin{tabular}{|c|c|c|c|c|c|c|c|}
\hline \multirow{2}{*}{ Position } & \multirow{2}{*}{ Treatment } & \multicolumn{3}{|c|}{ Number of impacts $\mathrm{cm}^{-2}$} & \multicolumn{2}{|c|}{ Coverage $\%$} & \multirow[b]{2}{*}{$\mathrm{CV}$} \\
\hline & & Average & STD & $\mathrm{CV}$ & Average & STD & \\
\hline \multirow[t]{2}{*}{$\mathrm{P} 1$} & $\mathrm{C}$ & 39 n.s. & 32 & 82 & 42 n.s. & 32 & 76 \\
\hline & M & 38 & 37 & 97 & 41 & 32 & 78 \\
\hline \multirow[t]{2}{*}{$\mathrm{P} 2$} & $\mathrm{C}$ & 98 n.s. & 68 & 69 & 20 n.s. & 12 & 90 \\
\hline & M & 100 & 67 & 67 & 12 & 11 & 92 \\
\hline \multirow[t]{2}{*}{$\mathrm{P} 3$} & $\mathrm{C}$ & 85 n.s. & 50 & 86 & 32 n.s. & 23 & 72 \\
\hline & M & 91 & 46 & 51 & 34 & 22 & 65 \\
\hline \multirow[t]{2}{*}{$\mathrm{P} 4$} & $\mathrm{C}$ & 86 n.s. & 80 & 93 & 21 n.s. & 19 & 90 \\
\hline & M & 124 & 65 & 52 & 28 & 21 & 75 \\
\hline \multirow[t]{2}{*}{ P5 } & $\mathrm{C}$ & 70 n.s. & 67 & 95 & 18 n.s. & 17 & 94 \\
\hline & M & 117 & 41 & 35 & 30 & 15 & 50 \\
\hline \multirow[t]{2}{*}{ P6 } & $\mathrm{C}$ & 116 n.s. & 64 & 55 & 16 n.s. & 14 & 87 \\
\hline & M & 109 & 63 & 58 & 16 & 15 & 94 \\
\hline
\end{tabular}

Tab. 2: Comparison between control (C) and modified (M) spray distribution: average, STD - standard deviation; CV - coefficient of variation of impacts $\mathrm{cm}^{-2}$ and coverage \% (5x3 trees); ${ }^{*}$ Significant Duncan test $\mathrm{p}<0.05 ;$ n.s. Non-significant

We can see that angling of upper spout downwards and lower spout upwards resulted in increase of number of impacts per unite are, but the increase was not statistically significant. At positions 4 and 5 number of impacts was increased, but 
not enough to get statistically significant difference. Also the increase in coverage rate was observed at position 4 from 21 to $28 \%$ and at position 5 from 18 to $30 \%$ (see Tab. 2). The results on number of impacts are in agreement with the results from (Moltó et al. 2001).

When spraying orchards, there are always cases when individual leaves have very high coverage causing individual impacts to heavily overlap. These leaves are usually located closer to the sprayer in the outer part of the tree (in our case positions P1, P3 and P5), while leaves inside dense crowns have lower coverage (in our case positions $\mathrm{P} 2, \mathrm{P} 4$ and $\mathrm{P} 6$ ). Consequently, the average number of impacts and coverage has to be discussed with the above condition in mind.

We can assume that angling of spouts improves the distribution and deposition of spray, only number of samples taken was too small to prove that statistically. We assume also that higher turbulence level and lower terminal velocity were achieved inside the crowns due to mixing of three airflows; however, no measurements were performed inside crowns to verify this assumption. It is also believed that better spray penetration was achieved when using MCM because of more adequate positioning of nozzles. In the case of the MCM spraying, the spray droplets swirl around propelled by the vortices of the turbulent air jet due to interference of three unparallel airflows from the sprayer and the tree structure. Panneton et al. (2005) reported similar conclusions about the airflow interaction with tree structure in the case of unparallel airflows. Positioning of spray nozzles was not controlled online. It is assumed that imaging algorithms can evolve in the future as already reported by Rovira-Más et al. (2005) to such an extent that it would be possible to detect the shape of trees and to guide simultaneously, not only the flow rate, but also the position the spray nozzles.

Tab. 3 shows the results on comparison of MCM and AM spraying modes. We can see that use of guidance system (AM) influenced the determined number of droplet impacts. At four of six positions in the trees the number of droplet impacts was significantly increased when sprayed in automated mode (see Tab. 3). The newly designed spraying arm operated under automated mode creates significantly more impacts in the inner P6 zone and outer P1 and P3 zones. There is a shift in droplet size distribution. The same influence of automation of spraying was not demonstrated in case of percent coverage. There were no statistically significant differences between MCM and AM spraying modes at any of analyzed positions.

Considering that coverage up to $30 \%$ ensures satisfactory control with most chemicals and agro-fogs (Hołownicki et al. 2002a), in both treatments the suggested threshold was exceeded: i.e., P1 and P3 in control spraying and P2 and P3 in automated spaying. However, the most important conclusion emerges when the number of impacts is taken into account together with the high level of coverage. As reported by Hołownicki et al. (2002a), the Optomax image algorithm calibrates itself by adjusting the threshold values before each series of WSP is processed. When the WSP is almost completely blue and coverage over $30 \%$ has been reached, the system is almost unable to count each individual impact. For this reason, the new threshold values can be automatically moved towards 1 (white values), which omitted small 
individual impacts; consequently, a lower number of impacts was reported (Hołownicki et al. 2002b).

In our case this threshold was set manually before the start of analysis of WSP by Optomax, so that all WSP were later processed using the same threshold setting. It was anticipated that differences between the control and automated spraying mode arise both because of turning nozzles on and off and because of the changed positioning of both types of nozzles on the automated sprayer. We are aware that a limited correlation between the WSP coverage values and true spray deposits measured by means of laboratory chemical (tracer) deposit analysis exists, therefore further analysis of deposits by means of laboratory measurements of deposits by chemical tracers will be evaluated in the next season. In our experiment we used a relatively small spray volume (272 1/ha), so a quite well relation between WSP coverage and the real deposit of chemicals can be assumed.

\begin{tabular}{|c|c|c|c|c|c|c|c|}
\hline \multirow{2}{*}{ Position } & \multirow{2}{*}{ Treatment } & \multicolumn{3}{|c|}{ Number of impacts $\mathrm{cm}^{-}$} & \multicolumn{3}{|c|}{ Coverage $\%$} \\
\hline & & Average & STD & $\mathrm{CV}$ & Average & STD & $\mathrm{CV}$ \\
\hline \multirow[t]{2}{*}{ P1 } & MCM & $38^{*}$ & 37 & 97 & 41 n.s. & 32 & 78 \\
\hline & $\mathrm{AM}$ & 133 & 78 & 59 & 24 & 22 & 92 \\
\hline \multirow[t]{2}{*}{$\mathrm{P} 2$} & MCM & 100 n.s. & 67 & 67 & 12 n.s. & 11 & 92 \\
\hline & $\mathrm{AM}$ & 113 & 105 & 93 & 35 & 33 & 94 \\
\hline \multirow[t]{2}{*}{ P3 } & MCM & $91^{*}$ & 46 & 51 & 34 n.s. & 22 & 65 \\
\hline & $\mathrm{AM}$ & 186 & 94 & 51 & 36 & 19 & 53 \\
\hline \multirow[t]{2}{*}{$\mathrm{P} 4$} & MCM & 124 n.s. & 65 & 52 & 28 n.s. & 21 & 75 \\
\hline & AM & 174 & 110 & 63 & 25 & 16 & 64 \\
\hline \multirow[t]{2}{*}{ P5 } & MCM & $117^{*}$ & 41 & 35 & 30 n.s. & 15 & 50 \\
\hline & AM & 160 & 103 & 64 & 27 & 24 & 89 \\
\hline \multirow[t]{2}{*}{ P6 } & MCM & 109 & 63 & 58 & 16 n.s. & 15 & 94 \\
\hline & $\mathrm{AM}$ & $186^{*}$ & 82 & 44 & 17 & 16 & 94 \\
\hline
\end{tabular}

Tab. 3. Comparison between modified (MCM) and automated (AM) spray distribution: average, STD - standard deviation; CV - coefficient of variation of impacts $\mathrm{cm}^{-2}$ and coverage \% (5x3 trees); * Significant Duncan test $\mathrm{p}<0.05$; n.s. Non-significant

It is common opinion that spraying with less liquid the remaining droplet size will cause smaller number of impacts. However, it was not the case in our experiment. We assume that fast opening and closing of nozzles influences the droplet size spectrum as well the distribution and disintegration of liquid in the air streams and liquid stream. We think the theoretical knowledge from the field of jet engines (Choo \& Kang 2003) could partly proof significant differences in the liquid 
disintegration to droplets in case of constant liquid jet, in comparison to irregularly pulsed liquid jet produced by the same nozzles and the same pressure.

In terms of coverage the spryer did not perform better when guided by image acquisition system. The image detection algorithm, unlike radar or ultrasound systems, was not able to detect the tree structure deep inside the tree crown. The applied RGB camera system captured only the 2D image projection of the tree row, which according to the results is insufficiently accurate for opening/closing both nozzles of the lower section. An additional reason for small differences between control spray mode (MCM) and automated spray mode (AM) may be that the droplets in the case of automated spray mode do not follow a straight trajectory from the nozzle to the canopy. Not all the droplets hit the theoretical target at the point taken in the account by the system algorithm.

\subsection{Reduction of spray used per area unit}

The working time and real-time flow rate of each particular nozzle for a test track is shown in Tab. 4. The effective working time for each nozzle was calculated as the sum of all opening times from the stored data of the valves' open/closed status during the driving along the track, while the real-time flow rate was calculated according to equations 1 and 2. The sequence of turning the nozzles on/off is explained in section 2.4 .

In the upper third of the tree crowns, the first nozzle of the above nozzle pair was closed $10.82 \mathrm{~s}, 72.13 \%$ of the time span of the experiment, while the second nozzle of the above nozzle pair was closed for $5.10 \mathrm{~s}(34.00 \%)$. The reason for such ration between on and off times lies in the spindle crown structure, because trees were trained in a conical shape, and thus forms significant windows or gaps without canopy structures between neighbouring trees.

In the middle of the crowns, the first nozzle of the middle nozzle pair was not closed at all, while the second nozzle of the middle nozzle pair was closed for $5.14 \mathrm{~s}$ (34.27\%). The main cause of such a distribution of closing times lies in the density of the tree crowns, which are most concentrated in the middle part of the height of the tree. On the other hand, some small gaps appeared in the middle of the crown height too.

In the below third of the tree crowns the situation was very similar; the first nozzle of the below nozzle pair was operating during the whole experiment, while the second nozzle of the below nozzle pair was closed for $0.11 \mathrm{~s}(0.73 \%)$. The closing time of the second nozzle was also connected to the gaps between neighbouring trees; in this part of the tree canopy the camera captured the structures of the rootstock and the lowest branches, which usually bear fewer leaves. In this particular position, the camera captured also the leaves and branches of trees in the adjacent row and ground vegetation. Later during image processing the algorithm was not able to discriminate both well enough. This may also be the reason for relatively shorter closing time of the below nozzles as one would expect due to the spindle growing crown which form substantial spaces between consecutive trees. 
As seen from the results above, the present development stage of RGB camera algorithm can not avoid capturing some structures of the adjacent trees for $100 \%$. However, we believe that such shortage will be avoided by further development of the image processing algorithm.

Given that the average operating time on the $20 \mathrm{~m}$ long experimental field track was $15 \mathrm{~s}$ per nozzle in the control spraying mode, and $11.47 \mathrm{~s}$ with the automated spraying mode, nozzles were closed on average, for $3.53 \mathrm{~s}$; thus calculated spray savings at an average of $23.53 \%$ were achieved for all six nozzles together. For that reason, a significant reduction of the average real-time flow rate per nozzle from $0.701 \mathrm{~min}^{-1}$ to $0.541 \mathrm{~min}^{-1}$ was achieved in comparison with spraying in control mode when the three 2-nozzle sections of the automated sprayer were not guided by the image algorithm system.

Other researchers reported higher spray savings with different type of sensors. Savings in different fruit orchards reported by Moltó et al. (2001) and Solanelles et al. (2006), ranged from $28 \%$ in a high density pear plantation to $68 \%$ in an older olive plantation, while controlling the sprayer nozzles with ultrasound sensors. Our results correspond with results of Koch et al. (1998) and Weisser \& Koch (2002). They have already explained how savings are directly correlated to the reduction of the oversprayed area which is again related to area cut out from total oversprayed canopy area by assistance of sensors. Data presented by Schmidt \& Koch (1995) and Koch \& Weisser $(1995,2000)$ confirm the good linear correlation between dose par unit area canopy wall and deposit on targets. We believe that our prototype sprayer supports that concept and that even simple 2D image guided sensor concept like ours can enable significant savings without reduction of quality of spray deposits and efficacy of plant protection chemicals.

$\mathrm{AM}$

\begin{tabular}{lllllll}
$\begin{array}{l}\text { Nozzle/ } \\
\text { deflector } \\
\text { position }\end{array}$ & $\begin{array}{l}\text { Open } \\
\text { time } \\
(\mathrm{sec})\end{array}$ & $\begin{array}{l}\text { Close } \\
\text { time } \\
(\mathrm{sec})\end{array}$ & $\begin{array}{l}\text { Real- } \\
\text { time } \\
\text { flow } \\
\text { rate } \\
\left(1 \mathrm{~min}^{-1}\right)\end{array}$ & $\begin{array}{l}\text { Open } \\
\text { time } \\
(\mathrm{sec})\end{array}$ & $\begin{array}{l}\text { Close } \\
\text { time } \\
(\mathrm{sec})\end{array}$ & $\begin{array}{l}\text { Real- } \\
\text { time } \\
\text { flow } \\
\text { rate } \\
\left(1 \mathrm{~min}^{-1}\right)\end{array}$ \\
\cline { 2 - 7 } $1^{\text {st }}$ above & $4.18^{\mathrm{a}}$ & 10.82 & 0.19 & 15.00 & 0.00 & 0.70 \\
$2^{\text {nd }}$ above & $9.90^{\mathrm{b}}$ & 5.10 & 0.47 & 15.00 & 0.00 & 0.70 \\
$1^{\text {st }}$ middle & $15.00^{\mathrm{c}}$ & 0.00 & 0.70 & 15.00 & 0.00 & 0.70 \\
$2^{\text {nd }}$ middle & $9.86^{\mathrm{b}}$ & 5.14 & 0.46 & 15.00 & 0.00 & 0.70 \\
$1^{\text {st }}$ below & $15.00^{\mathrm{c}}$ & 0.00 & 0.70 & 15.00 & 0.00 & 0.70 \\
$2^{\text {nd }}$ below & $14.89^{\mathrm{c}}$ & 0.11 & 0.69 & 15.00 & 0.00 & 0.70 \\
Average & 11.47 & 3.53 & 0.54 & 15.00 & 0.00 & 0.70 \\
Index R/C & 76.47 & 23.53 & 76.47 & & &
\end{tabular}

Tab. 4. Average working time (sec) and real-time flow rate $\left(1 \mathrm{~min}^{-1}\right)$ for automated (AM) and modified (MCM) spray distribution 
Stajnko, D.; Vindis, P. \& Mursec, B.: Automated System for Targeted Spraying in ...

\section{Future sprayer developments}

Assessment of our RGB image electronic control system for proportional spray application to the tree canopy (green wall area) in particular apple orchard showed in total a $23 \%$ savings of pesticides $\left(0.961 \mathrm{~min}^{-1}\right.$ flow rate reduction) by use of the automated spraying mode, in comparison to spraying in control mode. However, this is not enough to claim the same spray savings for diverse spraying applications in a number of orchards, planted with different fruit varieties with trees of varying shape and size. Saving were achieved without significant reduction of spray coverage at any tree position what makes the RGB camera approach interesting for further developments.

From the practical point of view we know, that one nozzle with $80-90^{\circ}$ angle is required to cower a bend of $0.5 \mathrm{~m}$ of tree crown if the nozzles are orientated perpendicularly to the tree green wall, and the nozzles are positioned round 0.3 to 0.5 $\mathrm{m}$ from the edge of tree crown. In our case, we have got six nozzles, which should be theoretically enough to cover a $3 \mathrm{~m}$ high tree crown, when assuming that the lowest $40 \mathrm{~cm}$ are not spayed. Practically, for sure, it would be better to have more spouts and nozzles, because in that case the ability of adopting the sprayer to trees would be better.

The novel design of spray arms could bring progress in spraying at farms with number of orchards of different training systems and age. When moving from orchard to orchard the sprayers spouts can be adopted easily to the tree canopy by simple setting from the cabin of the tractor. For instance, in the case of smaller trees we can switch off the upper pair of nozzles; or in the varying tree structure we can adopt the spouts by moving them vertically.

However, in order to measure the efficiency of our automated sprayer better, other quantitative methods of deposit assessment (i.e. tracer deposit analysis) need to be applied in future studies. Potential further improvement of our prototype system can be achieved by modifying the position of the camera or estimating the tree canopy volume by the scanning the tree canopy by a stereo camera system and by additional algorithm improvements that have the better capacity to visualize the extensive area of leaf density in the middle of the crown and give better discrimination of tree crown and the background also in the lower section of the trees.

\section{Acknowledgements}

This research was funded by ARRS No. 430-32/2006-31 as part a of joint Slovenian-Israeli bilateral project. The funding is gratefully acknowledged. The authors also acknowledge the vital contributions made by the following colleagues: Matjaž Sagadin, who was responsible for the field measurements; a technician and a tractor driver, Toni Gjergek; and Roman Mauc, the head of the experimental orchard in Brdo pri Lukovici, who was always willing to help during the measurements in the orchard; and to Professor Michelle Gadpaille, for her editing of the manuscript. 


\section{References}

Byers, R.E., Hickey, K.D. \& Hill, C.H. (1971). Base gallonage per acre. Virginia Fruit 60, 19-23, USA

Choo, Y.J. \& Kang, B.S. (2003). A study on the velocity characteristics of the liquid elements produced by two impinging jets, 34, 655-661. Experiment in Fluids ISSN: 0723-4864, Springer, USA

Cross, J.V., Walklate, P.J., Murray, R.A. \& Richardson, G.M. (2001). Spray deposits and losses in different sized apple trees from an axial fan orchard sprayer: 1. Effects of spray liquid flow rate, 20, 13-30, Crop Protection, ISSN 0261-2194, Elsevier, Netherlands

Gil, E., Escolà, A., Rosell, J.R., Planas, S. \& Vald. L. (2007). Variable rate application of plant protection products in vineyard using ultrasonic sensors, 26, 1287-1297, Crop Protection, ISSN 0261-2194, Elsevier, Netherlands

Heijne, B., Doruchowski, G., Holownicki, R., Koch, H., Jaeken, P., Siegfried, W., Hollinger, E., Cross, J.V. \& Orts, R. (1997). Developments in spray application techniques in European pome fruit growing. IOBC/WPRS B. 20, 119-129

Hołownicki, R., Doruchowski, G., Godyn, A. \& Swiechowski, W. (2002a). Variation of Spray Deposit and Loss with Air-jet Directions applied in Orchards, 77, 129-136, Journal of Agricultural Engineering, ISSN 0021-8634, Elsevier Science, Netherlands

Hołownicki, R., Doruchowski, G., Świechowski, W. \& Jaeken, P. (2002b). Methods of evaluation of spray deposit and coverage on artificial targets. Available Online: http://www.ejpau.media.pl/volume5/issue1/engineering/art-03.html., Electronic Journal of Polish Agricultural University, ISSN 1505-0297

Kise, M., Zhang, Q. \& Rovira-Más, F. (2005). A stereovision-based crop row detection method for tractor-automated guidance, 90, 357-367, Biosystems Engineering, ISSN: 1537-5110, Elsevier Science, Netherlands

Koch, H. \& Weisser, P. (1995). Dose rate and initial deposit - two major parameters of pesticide application, 47, 273-278, Nachrichtenbl. Deut. Pflanzenschutzd. ISSN 0027-7479, Germany

Koch, H., Weisser, P., Funke, H. G. \& Knewitz, H. (1998). Investigations of distrubution characteristic of single nozzles during pesticide application with air assisted orchard sprayers, 50, 30-36, Nachrichtenbl. Deut. Pflanzenschutzd. ISSN 0027-7479, Germany

Koch, H. \& Weisser, P. (2000). Sensor equipped orchard spraying - efficacy, savings and drift reduction, 57, 357-362, Annals of Applied Biology, ISSN: 00034746, UK

Moltó, E., Martín, B. \& Gutiérrez, A. (2000). Design and testing of an automatic machine for spraying at a constant distance from the tree canopy, 77, 379-384, Journal of Agricultural Engineering, Elsevier Science. ISSN 0021-8634, Nederlands

Moltó, E., Martín, B. \& Gutiérrez, A. (2001). Pesticide loss reduction by automatic adoption of spraying on globular trees, 78, 35-41, Journal of Agricultural Engineering, Elsevier Science. ISSN 0021-8634, Nederlands 
Stajnko, D.; Vindis, P. \& Mursec, B.: Automated System for Targeted Spraying in ...

Panneton, B., Lacasse, B. \& Piché, M. (2005). Effect of air-jet configuration on spray coverage in vineyards, 90, 173-184, Biosystems Engineering, ISSN: 15375110, Elsevier, Nederlands

Pergher, G., Gubiani, R. \& Tonetto, G. (1997). Foliar deposition and pesticide losses from three air-assisted sprayers in a hedgerow vineyard, 16, 25-33, Crop Protection, ISSN 0261-2194, Elsevier, Nederlands

Pergher, G. \& Petris, R. (2008). Pesticide dose adjustment in vineyard spraying and potential for dose reduction. The CIGR Ejournal 10, Manuscript ALNARP 08 011, ISSN 1682-1130

Rovira-Más, F., Zhang, Q., Reid, J. F. \& Will, J. D. (2005). Hough-transform-based vision algorithm for crop row detection of an automated agricultural vehicle, 219, 999-1010, Journal of Automobile Engineering, ISSN 0954-4070. SAGE

Schmidt, K. \& Koch, H. (1995): Adjustment of airblast sprayers and distribution of pesticide deposits in orchards, 47, 161-167, Nachrichtenbl. Deut. Pflanzenschutzd, ISSN 0027-7479, Germany

Schumann, A.W. \& Zaman, Q. U. M. (2005). Software development for real-time ultrasonic mapping of tree canopy size, 47, 25-40, Computers and Electronics in Agriculture, Elsevier Science. ISSN 0168-1699, Nederlands

Solanelles, F., Escolà, A., Planas, S., Rosell, J. R., Camp, F. \& Gràcia, F. (2006). An Electronic control system for pesticide application proportional to the canopy width of tree crops, 95, 473-481, Biosystems Engineering, ISSN: 1537-5110, Nederlands

Sutton, T.B. \& Unrath, C.R. (1984). Evaluation of the Tree-Row-Volume concept with density adjustments in relation to spray deposits in apple orchards, 68, 480-484, Plant Disease, ISSN 0191-2917, PS Journals, USA

Sutton, T.B. \& Unrath, C.R., (1988). Evaluation of the Tree-Row-Volume model for full-season pesticide application on apples, 72, 629-632, Plant Disease, ISSN 0191-2917. APS Journals, USA

Van de Zande, J. C., Achten, V. T. J. M., Michielsen, J. M. G. P, Wenneker, M. \& Kostner, A. T. J. (2008). Towards more target oriented crop protection. International advances in pesticide application, 84, 1245-1252, Aspects of Applied Biology, ISSN 0265-1491, UK

Wangler, R. J., Connell, R. E., Fowler, K. L. \& Olson, R. A. (1993). Application of smart submunition technology to agribusiness. In: J.A. DeShazer, G.E. Meyer (eds.): Proc. SPIE, vol. 1836, pp. 261-272, Optics in Agriculture and Forestry

Walklate, P. J., Cross, J. V., Richardson, G. M ., Murray, R. A. \& Baker, D. E., (2002). Comparison of Different Spray Volume Deposition Models Using LIDAR Measurements of Apple Orchards, 82, 253-267, Biosystems Engineering, ISSN 1537-5110, Nederlands

Weisser, P. \& Koch. H. (2002). Expression of dose rate with respect to orchard sprayer function, 66, 353-358, Annals of Applied Biology, ISSN 0003-4746, UK 